\title{
La transgresión del derecho de participación por la alternabilidad. Estudio de la
} reelección indefinida

\section{The transgression of the participation right by the alternation. Study of indefinite} reelection

Raúl Andres Ortega-Pineda

raul.ortega@psg.ucacue.edu.ec

Universidad Católica de Cuenca, Cuenca

Ecuador

https://orcid.org/0000-0002-5356-1237

Cecilia Ivonne Narváez-Zurita

inarvaez@ucacue.edu.ec

Universidad Católica de Cuenca, Cuenca

Ecuador

https://orcid.org/0000-0002-7437-9880

Juan Carlos Erazo-Álvarez

jcerazo@ucacue.edu.ec

Universidad Católica de Cuenca, Cuenca

Ecuador

https://orcid.org/0000-0001-6480-2270

José Luis Vázquez-Calle

jlvazquezc@ucacue.edu.ec

Universidad Católica de Cuenca, Cuenca

Ecuador

https://orcid.org/0000-0003-1809-1601

Recibido: 15 de abril de 2020

Revisado: 17 de mayo de 2020

Aprobado: 25 de mayo de 2020

Publicado: 14 de junio de 2020 


\title{
RESUMEN
}

El derecho de participación es utilizado por la ciudadanía para intervenir en actos públicos del Estado, siendo una de las formas más puras de participación el sufragio en condiciones democráticas y justas como mecanismo de garantía de las demandas de la sociedad. Sin embargo, en Ecuador el derecho de participación se ve trasgredido al limitar la reelección indefinida, bajo este contexto, se propone realizar una enmienda de la Constitución de los artículos 114 y 144 referidos al número de postulaciones. En la investigación se aplicó la metodología descriptiva- explicativa; en la fase de diagnóstico se concluyó que la aprobación de la consulta popular efectuada en el año 2018 negó la figura de postulación para la reelección indefinida con carácter popular vulnerando el derecho de igualdad y participación política ciudadana consagrado en la Constitución de la República, entendiéndose como una restricción y regresión injustificada de derechos.

Descriptores: Participación política; democracia; constitución; soberanía. (Palabras tomadas de Tesauro UNESCO).

\begin{abstract}
The right of participation is used by citizens to intervene in public acts of the State, being one of the purest forms of participation suffrage in democratic and fair conditions as a mechanism to guarantee the demands of society. However, in Ecuador the right to participation is violated by limiting indefinite reelection, in this context, it is proposed to make an amendment to the Constitution of articles 114 and 144 referring to the number of applications. In the research the descriptive-explanatory methodology was applied; In the diagnostic phase, it was concluded that the approval of the popular consultation carried out in 2018 denied the figure of nomination for indefinite reelection with popular character, violating the right of equality and citizen political participation enshrined in the Constitution of the Republic, understood as an unjustified restriction and regression of rights.
\end{abstract}

Descriptors: Political participation, democracy, constitutions, sovereignty. (words taken from UNESCO Thesaurus).

\section{INTRODUCCIÓN}

En el presente artículo se estudia el derecho de participación política de la sociedad en cuanto a su intervención en el ámbito de elegir y ser elegido. En el Estado ecuatoriano al surgir la presencia de la Constitución de la República del Ecuador (CRE) del año 2008, 
rige el ejemplar Estado Constitucional de derechos o también llamado neo Constitucionalismo, es decir, un modelo de Estado mucho más garantista en derechos que abarca de forma muy amplia un sin número de derechos y garantías constitucionales, entre otros, los derechos civiles y políticos que hoy se los conoce como derechos de participación (Nivelo, Erazo, Guerra, \& Narváez, 2020) y (Robles, Erazo, Trelles, \& Narváez, 2020).

Considerado que los derechos no son absolutos y por su naturaleza ceden ante la aparición o aplicación de otros derechos, se investigó si al aplicar el principio de alternabilidad en el Estado ecuatoriano se trasgrede el derecho de participación por la manera en la que se coarta el derecho de elegir y ser elegido (Asamblea Nacional del Ecuador, 2012). En el contexto de esta problemática se evidencia una clara regresión de derechos de participación por parte de la Corte Constitucional del Ecuador, al no respetarse el (Dictamen N N 001-14-DRC-CC, 2014), que abarca un amplia proteción de derechos de participación y garantías jurisdicionales, por el hecho de no emitir el dictamen previo de constitucionalidad de las preguntas efectuadas mediante consulta popular en el año 2018 y al emitir de forma posterior la (Sentencia Nº18-18-SIN-CC, 2018) que declara la incosntitucionaledad por la forma de las enmiendas, aprobadas el 03 de diciembre de 2015.

La investigación de esta problemática social se realizó por el interés de conocer porque se permitió la regresión de derechos en el Estado ecuatoriano donde prevalece el reconocimiento de forma más amplia de los mismos. La problemática fue planteada desde un interés académico ya que se busca establecer y verificar si la aplicación del principio de alternabilidad trasgrede el derecho de participación.

Con estas referencias expuestas, se plantea el siguiente problema de investigación: ¿Cómo afecta la prohibición de la reelección indefinida sobre el derecho de participación y democracia en la sociedad? Partiendo de esta problemática, la presente investigación tiene como objetivo: proponer una enmienda de la Constitución a los artículo 114 y 144 referidos al número de postulaciones con la finalidad de respetar lo emitido por la Corte Constitucional en el dictamen 001-14-DRC-CC-2014 sobre la reelección indefinida. 


\section{Referencial Teórico}

\section{Derecho de participación en el Ecuador}

El derecho de participación también conocido como derechos políticos ha evolucionado acorde a los cambios y la lucha de la sociedad, dado que en poblaciones anteriores solo eran otorgados a ciertos grupos de personas y no para toda la población, características que se han modificado y mejorado en la sociedad en particular el derecho de elegir y ser elegido, ya que se han eliminado cada vez más obstáculos para que toda la población en la actualidad goce de este derecho (Nivelo, Erazo, Guerra, \& Narváez, 2020).

El derecho de participación permite a los ciudadanos contribuir en la orientación de los contenidos públicos, como son votar, elegir y ser elegidos en circunstancias habituales, justas, auténticas y democráticas con la finalidad de ejercer sus derechos como ciudadanos, enmarcados en métodos democráticos establecidos con aprobación de la ciudadanía que garanticen su satisfacción, sin importar el modelo de gobierno que adopte el Estado.

Para (Nieto \& Romero, 2017) el derecho de participación se originó con el objetivo de alcanzar una democracia basada en la voluntad de las personas y el reconocimiento de los derechos de manera individual y colectiva, en este sentido, la democracia participativa no solo se enfoca en el alcance político sino también en el social. La participación es un derecho a través del cual de forma libre los ciudadanos pueden ejercer su voluntad democrática, garantizando que la libertad de expresión sea el límite y principio de la autenticidad de su ejercicio, mientras esté relacionado a los asuntos públicos. De esta forma el Estado debe efectuar medidas eficaces para asegurar que todas las personas ejerzan los derechos de participación, accedan al derecho al voto, y a postularse en el caso de cumplir los requisitos mínimos determinados en la Constitución.

Dentro de este contexto, la Constitución Política del Ecuador de 1998 contemplaba en sus enunciados el derecho de participación como un elemento inherente de los ciudadanos, siendo considerado un derecho de segunda generación, la misma tenía la finalidad de ejecutar el contrato social entre el pueblo y el Estado. En este marco jurídico queda claro el método de participación política, ya que en su artículo 98 manda que las 
organizaciones políticas reconocidas podrán presentar su candidato para la dignidad de elección popular haciendo alusión a que se faculta la reelección indefinida (Asamblea Nacional Constituyente, 1998), por lo tanto, no restringía el derecho de participación, en referencia al número de postulaciones de los candidatos que aspiraban a un cargo de elección popular al aceptar la reelección indefinida.

En la actualidad, la (Asamblea Nacional Constituyente, 2008) manifiesta como principio de participación que los ciudadanos y ciudadanas de manera individual o colectiva pueden participar en la toma de decisiones, en conjunto con la planificación, dirección de cuestiones públicas e intervención ciudadana de las instituciones del Estado y la colectividad, basándose en principios de autonomía, igualdad, respeto a la diferencia, control popular, deliberación publica, enmarcados en mecanismos de democracia representativa y comunitaria.

La Constitución del Ecuador establece en el artículo 1 que el Estado es un sistema democrático que debe ser abordado desde la concepción de los derechos constitucionales de participación de la población para así permitir el desarrollo de los poderes públicos con un equilibrio en las fuerzas políticas (Asamblea Nacional Constituyente, 2008). Sobre la base de este análisis, la elección de autoridades está relacionada con los mecanismos de participación directa dentro del Estado ecuatoriano, a través de un proceso trasparente, democrático y de confianza extrema, ya que el electorado escoge a sus mandantes y la vez se involucra de manera absoluta en la toma de decisiones.

Sin embrago, el Estado ecuatoriano al definir como uno de los mecanismos principales de participación la democracia participativa, se contradice en su accionar, ya que la Constitución del Ecuador del año 2008 establece: "Las autoridades de elección popular podrán reelegirse por una sola vez, consecutiva o no, para el mismo cargo. Las autoridades de elección popular que se postulen para un cargo diferente deberán renunciar al que desempeñan" (Asamblea Nacional Constituyente, 2008, art.114). Al respecto, se debe precisar que lo establecido en el artículo precedente, configura una trasgresión clara al derecho de participación, contradiciendo de forma amplia lo 
establecido en el artículo 95 del mismo cuerpo normativo.

Esta restricción aplica tanto para los votantes como para los ciudadanos que aspiran a un compromiso de elección popular, ya que los interesados de continuar un mandato por tercera vez de un candidato que de forma correcta ejerza su cargo de elección popular, no lo pueden hacer por la prohibición expresa del artículo 144 de la Constitución del 2008. En el año 2014, la Corte Constitucional del Ecuador en conformidad con el apartado 443 de la Carta Magna, y en concordancia con el apartado 101 de la Ley Orgánica de Garantías Jurisdiccionales y Control Constitucional, se pronunció sobre el procedimiento a seguir para modificar la Constitución, en cuanto a la eliminación de la frase por una sola vez del artículo 144, como se puede observar en la tabla 1.

\section{Tabla 1}

Modificación propuesta del artículo 144

Articulo 144

Vigente

"Art. 144.- segundo incisos:

La presidenta o presidente de la La presidenta 0 presidente de la república permanecerá cuatro años en república permanecerá cuatro años en sus funciones y podrá ser reelecto por sus funciones y podrá ser reelecto"

\section{una sola vez"}

Fuente: (Dictamen Nº01-14-DRC-CC, 2014).

La Corte Constitucional ecuatoriana resolvió que el propósito debía ser tramitado por la vía de enmienda, dado que no afectaba los límites impuestos por el artículo 441 de la Constitución (Dictamen № 001-14-DRC-CC, 2014). El máximo órgano de interpretación constitucional del Estado ecuatoriano atreves del (Dictamen № 001-14-DRC-CC, 2014) establece que, al existir un Estado democrático éste debe garantizar una amplia participación y permitir el desarrollo de la intervención democrática de la sociedad, ya que es el único medio para afianzar un equilibrio de los poderes estatales. Para la Corte 
Constitucional la toma de decisiones de los ciudadanos es la fuente de legitimidad, con la cual la decisión libre de elegir la ejerce el pueblo, respetando así su democracia y la oportunidad de ser candidato.

A partir de la interpretación realizada por la Corte Constitucional ecuatoriana se colige que el derecho de participación debe ejecutarse de manera igualitaria sin restricciones injustificadas, bajo este precepto, el derecho de elegir y ser elegido se contrapone al impedir la reelección por más de una vez de las personas que quieren acceder a este derecho. En consecuencia, el dictamen 001-14-DRC-CC establece que no es razonable la limitación del derecho de participación para quien pretenda ser reelegido, ya que contaría con las mismas condiciones que el resto de participantes por las prohibiciones dispuestas en la Constitución en cuanto al uso de fondos públicos e infraestructuras del Estado.

De forma complementaria, la Corte en el dictamen antes referido pronuncia que la modificación del artículo 144 referente a la reelección indefinida, no restringe derechos más bien busca ampliarlos, afianzado el derecho de participación para que el pueblo soberano sea quien elija a sus representantes. A pesar de lo expuesto, la Corte Constitucional del Ecuador en el año 2018 declara la inconstitucional de las enmiendas que mediante dictamen sostuvo que la vía correcta es la reforma ya que las mismas no alteraban los elementos constitutivos del Estado.

La Corte Constitucional, mediante de su dictamen N. 001-14-DRC-CC, expresó el proceso que correspondía continuar para las modificaciones planteadas, siendo la enmienda Constitucional. Una vez cumplida la gestión ordenada por la Corte, y revisado su acatamiento, las correcciones estuvieron publicadas en el Registro Oficial. La Corte establece que se siguió el procedimiento correcto para formalizar las modificaciones constitucionales siendo estás ya analizadas y de cumplimiento obligatorio (Sentencia $\left.\mathrm{N}^{\circ} 018-18-\mathrm{SIN}-\mathrm{CC}, 2018\right)$.

En el auto de verificación del (Dictamen Nº01-14-DRC-CC, 2014) de procedimiento efectuado por la Corte Constitucional, se establece la inexistencia de vicios formales en la sustanciación del proceso y validación de las enmiendas. En tal sentido, señala. 
"Consecuentemente, en el caso que nos ocupa, queda demostrado de manera clara y absoluta que las enmiendas han sido aprobadas con total sujeción a la Constitución y a la ley" (Sentencia N018-18-SIN-CC, p. 62).

La Corte determina que no es viable verificar un control sobre el lecho de un precepto Constitucional ya decretado sobre la base de lo prevenido en el apartado 106 de la Ley Orgánica De Garantías Jurisdiccionales y Control Constitucional, ya que con anterioridad se efectuó dicha revisión en relación con la proposición de enmienda, reforma o cambio. El examen de mandato previo se ejerció mediante la declaración del dictamen de procedimiento en relación a la proposición de modificar la Norma Suprema. (Sentencia N018-18-SIN-CC, 2018) (Asamblea Nacional del Ecuador, 2009)

En consecuencia resulta absurdo que la Corte Constitucional deje sin efecto a las enmiendas constitucionales por la forma de procedimiento y aprobación ya que las mismas fueron votadas por la Asamblea Nacional en bloque y no de forma particular, siendo un asunto meramente interno del órgano Legislativo siendo imposible considerar esto como un vicio de procedimiento y aprobación, así queda demostrada la regresión injustificada que sufrió el derecho de participación.

\section{Análisis al principio de alternabilidad en el Ecuador}

El principio que ahora se estudia es conocido y aplicado como uno de los métodos más eficaces para poner fin a las dictaduras que pretendan apoderarse de un Estado, afirmando que el principio de alternabilidad fue concebido a través de la historia para desafiar las ambiciones de permanencia en el poderío, evitando el continuismo y posibles ventajas que se presenten en los procesos electorales (Brewer-Carias, 2009).

Se pretende que en el Estado ecuatoriano el principio de alternabilidad sea visto por la ciudadanía como un elemento constitutivo del Estado que sirve para garantizar el control del poder en el régimen democrático y así nadie subsista de manera indeterminada en el poder. A partir de esta definición se puede considerar al principio de alternabilidad como un elemento constitutivo del Estado.

La Corte Constitucional en el dictamen Nº01-14-DRC-CC emitido en el 2014, el cual 
buscaba eliminar la restricción a la postulación y posible reafirmación de autoridades de elección popular por la eliminación de la palabra por una sola vez determinada en el artículo 144 inciso segundo de la Constitución del año 2008, se plantea la siguiente pregunta: 1) ¿Se puede considerar como elemento constitutivo del Estado a la democracia y alternabilidad?

Al respecto, la Corte Constitucional expone que la democracia se entiende como el conglomerado de procedimiento y reglas para la alineación de disposiciones agrupadas, que facilitan la más amplia colaboración posible de los interesados, así la Corte considera que lo más importante en el aparato esencial de la democracia estatal es la contribución de la población en la toma de las medidas basadas en mecanismos de aportación en torno a forjar la más amplia intervención viable del pueblo, según lo dispuesto en la constitución ecuatoriana del 2008 artículo 95 (Dictamen Nº01-14-DRC-CC, 2014).

En definitiva en base al dictamen emitido por la Corte el sistema democrático ecuatoriano se fundamenta en el respeto del contrato social entre el Estado y el pueblo ya que es primordial la participación directa de las ciudadanas y ciudadanos en el ámbito de la política de un Estado, llegando a la conclusión que la alternabilidad no constituye un elemento constitutivo del Estado por no estar incluido en el artículo 1 de la constitución, resultando él voto el instrumento a utilizar para la aplicación del principio de alternabilidad y con ello verificar si el mismo se hace o no presente. El principio de alternabilidad tendría que ser aplicado como el elemento que el pueblo, con poder constituyente creado y aprobado, se debería imponer así mismo, con la finalidad de decidir entre galardonar a quienes estime como su mejor gobernante, o bien revocar a un mandatario cuando su desempeño haya sido pobre.

(Penfold, Corrales, \& Hernández, 2014) Señalan que los países que prohíben la reelección indefinida no han sufrido ningún cambio sustancial en la Constitución, estableciendo que al existir este tipo de restricción podría ser más difícil reformarla. En este sentido, la Constitución ecuatoriana en sus artículos 114 y 144 prohibían la reelección indefinida, sin embargo, no fue complicado reformar esta norma dejando inaplicable el concepto de los autores antes citados. 
En el Ecuador se utiliza de forma errada el principio de alternabilidad que como todos los principios se efectivizan y ejercen a través de los derechos, siendo los ciudadanos los titulares de este derecho queda facultado en ellos elegir a su mandante, y de ser correcto y necesario la continuidad de algún mandatario, no obstante, en el Ecuador se utiliza el principio de alternabilidad como un limitante que transgrede el derecho de participación. En la constitución se reconoce a la alternabilidad como un método de articulación de las organizaciones políticas mas no como un elemento constitutivo del Estado ya que el artículo 96 establece que: "Las organizaciones podrán articularse en diferentes niveles para fortalecer el poder ciudadano y sus formas de expresión; deberán garantizar la democracia interna, la alternabilidad de sus dirigentes y la rendición de cuentas" (Asamblea Nacional Constituyente, 2008, art.96). En síntesis, queda claro que el principio de alternabilidad no forma parte del elemento constitutivo de Estado ecuatoriano, por tanto, su aplicabilidad parte de la voluntad de los ciudadanos al momento de permitir o no que alguien contiene su mandato.

\section{Democracia participativa y Reelección indefinida}

Se conoce como democracia el sistema que protege la soberanía o voluntad del pueblo y el derecho que tiene la población a elegir a sus gobernantes. La democracia puede ser comprendida como un régimen político enmarcado en un estilo de gobierno y como una forma de cultura ligada a la vida, emparentada siempre al ámbito público por la intervención de las poblaciones (Sanchéz, 2003).

Como lo manifiesta (Baños, 2006), la democracia se torna en varios modelos, tales como: liberal, participativa y radical; modelos alternativos que si bien son diferentes, buscan un mismo resultado que se respete la voluntad de los ciudadanos. La democracia participativa busca que su naturaleza radique en la participación de los ciudadanos con la toma de decisiones importes con relación a sus derechos.

Es sabido que en la década de los sesenta, la idea de participación ingresa en el vocabulario político público de Norte América con el impulso de estudiantes universitarios por tener nuevos espacios de intervención en la esfera de la educación superior y en el 
contexto de la lucha por los derechos civiles, a causa de la guerra de Vietnam en Estados Unidos existieron un sin número de demandas de grupos exigiendo se reconozcan los ahora llamados derechos de participación al tratar de fomentar una mayor participación de los ciudadanos, aquí surgió el primer intento por corregir la democracia (Baños, 2006). Como señala (Held, 1991), el interés fundamental de la democracia participativa es aumentar la intervención de los ciudadanos como componente para equilibrar el poder de los gobernantes y así sean tomados en cuenta intereses ultrajados de la sociedad. Todas las personas legalmente capaces poseen el derecho a participar como votantes y pretendientes en deliberaciones auténticas, libres y periódicas, ejecutadas por voto secreto mediante sufragio que avale su voluntad. Al respecto, Hamilton citado en (Serrafero, 2011) considerado como uno de los grandes tratadistas y defensores de esta problemática, señala que "la reelección era necesaria para que el pueblo pudiera prolongar el mandato presidencial cuando se aprobara su gestión y así seguir aprovechando los méritos y virtudes del mandatario" (p. 8). Resulta una exageración que se imposibilite a la ciudadanía a conservar en funciones aquellas personas que desde su óptica han trabajado y son acreedores de la confianza y aceptación de su población (Ibídem).

La Declaración Universal de Derecho Humanos en su artículo 21 numerales 1 y 3 establecen y reconocen que todas las personas tienen el derecho de elegir libremente a su representante y así participar de manera indirecta en su gobierno, enfatizando que la voluntad del pueblo es el pilar fundamental del poder público, esta voluntad se expresa mediante elecciones populares auténticas, periódicas practicadas a través del sufragio secreto que garantice la libertad del voto (Asamblea General de las Naciones Unidas, 1948).

De acuerdo con el artículo 424 de la (Asamblea Nacional Constituyente, 2008) se establece que los tratados internacionales ratificados en el Ecuador que reconozcan de mejor forma los derechos prevalecerán sobre cualquier otra norma jurídica, así el Estado ecuatoriano se encuentra obligado a emplear los tratados e instrumentos internacionales por sobre la Constitución. 
Al haber internacionalizado derechos políticos más favorables enunciados en el artículo 23 de la Convención Americana de Derechos Humanos (CADH) estos tendrían que prevalecer en el ordenamiento jurídico ecuatoriano, los mismos consisten en participar de los asuntos públicos mediante delegados libremente elegidos, votar, elegir y ser elegido en votaciones habituales que garanticen la libre manifestación e intención de los electores y lo más importante acceder en circunstancias iguales a las ocupaciones públicas del Estado (Organización de los Estados Americanos, 1969).

El Ecuador al reconocer los diferentes instrumentos internacionales está obligado a cumplirlos sobre la base de lo señalado por el artículo 2.2 de la carta de organizaciones de naciones unidad en virtud al principio pacta sunt servanda, principio universal del derecho internacional que debe ser cumplido fielmente por las partes de buena fe, de no respetarlo surge la figura de responsabilidad internacional que perturbaría al Estado ecuatoriano (Sentencia Constitucional Plurinacional 0084/2017, 2017).

Por otro lado, la Corte Constitucional del Ecuador establece que la posibilidad de que una persona pueda ser candidato por más de una vez siempre será sometida a un proceso electoral el mismo que tendrá que contar con la trasparecía y legitimidad en la cual el pueblo decida si debe conservar o no a sus autoridades. Analizándolo desde esta óptica, la reelección siempre considera y determina dos puntos de vista, "toda vez que, por un lado, se genera una facultad de la persona a elegir a sus representantes y, por otro lado, la de ser electo por el conglomerado" (Dictamen № 001-14-DRC-CC, 2014, pág.61).

Por lo tanto, la opción de ser candidato consolida la participación de la población, puesto que aquellas personas que pretendan ser reelegidos por más de una vez deberán siempre presentarse a un proceso de elección democrático en el que la población legalmente capaz resolverá su reelección, certificando de esta manera el sistema democrático participativo con relación a la designación de mandatario de un Estado democrático, como ya se analizó.

En conclusión la Constitución ecuatoriana, enmarcada en democracia, autoriza a la población en general a colaborar en la cimentación del poderío ciudadano, estableciendo como componente céntrico la participación y el principio de igualdad, ya que se lo 
efectiviza para las personas que ejecutan su derecho de elegir, como hacia las personas que desean ser seleccionados dentro de un proceso de elección popular, siendo el voto constitucional la fuente de legalidad fundamental, ratificando que la postulación a la reelección no es el único componente para otorgar el ejercicio del cargo público, pues es obligatorio y se requiere que sean seleccionados por el pueblo como el favorito (Ibídem).

\section{MÉTODO}

La presente investigación se enmarcó en un diseño no exploratorio de cohorte transversal, y alcance descriptivo - explicativo, se llevó a cabo estudiando el derecho constitucional de participación, su posible trasgresión al momento de aplicar el principio de alternabilidad, con enfoque en la prohibición de la reelección indefinida. La información para la organización del artículo fue levantada y analizada de los Convenios, Tratados Internacionales suscritos y ratificados por en el ordenamiento jurídico del Ecuador, Constitución Política del Ecuador 1998, Constitución de la República del Ecuador 2008, leyes, libros, sentencias, dictámenes, revistas jurídicas y diferentes artículos publicados en revista científicas indexadas como SciELO, Dialnet y lustitia Socialis Revista Arbitraria de Ciencias Jurídicas, tomadas en cuenta por su relevancia en la materia de estudio.

El enfoque de la investigación fue mixto, con énfasis en el método cualitativo ya que se efectuó un proceso de absoluta revisión bibliográfica a principios, derechos, teorías, normas infra constitucionales, estudio de casos emitido por la Corte Constitucional ecuatoriana y el cambio de concepto en el Ecuador de democracia representativa a participativa, este enfoque permitió obtener la información detallada para comprender la consecuencia de la investigación a su vez se aplicó el método cuantitativo con la aplicación de estadística inferencial, la misma que facilitó el procesamiento de datos obtenidos a partir de la aplicación de encuestas.

Los métodos empleados en la investigación fueron analítico-sintético, los mismos que permitieron en el trascurso del estudio analizar las características relevantes en relación al derecho de participación, como al principio de alternabilidad con sus consecuencias en 
la reelección indefinida, y además cómo método complementario se utilizó el inductivodeductivo ya que se logró conocer y explicar la importancia del derecho de participación para definir en qué momento surge la aplicación al principio de alternabilidad.

La muestra del presente artículo fue determinada efectuando un muestreo por conveniencia sustentando en la técnica aleatoria - no probabilística, en la cual se contó con la participación voluntaria de 25 ciudadanos, 8 abogados en libre ejercicio y 5 abogados vinculados al ámbito político.

\section{RESULTADOS}

Las encuestas realizadas sobre el derecho de participación y su trasgresión por el principio de alternabilidad con enfoque en la reelección indefinida, es la modalidad aplicada en esta investigación para demostrar la vulneración al principio de participación. Tomando en consideración que el estudio fue riguroso con análisis académico y por el tipo de estudio planteado fue posible contar con la participación de la ciudadanía en general y profesionales del derecho con conocimientos en el ámbito político. Así la investigación se orientó a determinar que la elaboración del estudio no solo conlleva propósitos explícitos, por consiguiente, se pudo establecer el nivel de apreciación de las personas que formaron parte de la unidad de análisis sobre la aplicabilidad del derecho de participación y su trasgresión por el principio de alternabilidad al prohibir la reelección indefinida.

Se estructuraron dos encuestas, la primera se conformó de 8 preguntas con respuestas preestablecidas y fueron aplicadas a 13 abogados y la segunda encuesta se conformó de 7 preguntas con respuestas preestablecidas y se aplicó a 25 ciudadanos ubicados en las diferentes ciudades del territorio ecuatoriano. La clasificación y estudio de la información obtenida compone la motivación científica para la identificación del problema investigado.

La primera pregunta aplicada en las dos encuestas fue similar teniendo como objetivo investigar si las personas que formaron parte del mecanismo de análisis poseen conocimientos e interés sobre el Derecho Constitucional. De este modo, al momento de 
ser consultados sobre que entienden por derecho de participación, resultó que el $80 \%$ de los profesionales del derecho y $60 \%$ de la ciudadanía en general tienen conocimiento sobre los derechos de participación.

En referencia a la encuesta aplicada a la ciudadanía, el 100\% de los encuestados estiman conveniente la participación directa de los ciudadanos en el ámbito de la política de un Estado. Al saber que la población encuestada consideró importante la participación ciudadana, este resultado dio lugar a que el 92\% (ver figura 1) de la población crea conveniente que sea la ciudadanía quien, decida sobre una posible reelección; de forma complementaria, el $64 \%$ de la población encuestada concluyó que el principio de alternabilidad es aplicado para prohibir la reelección indefinida, mientras que un $36 \%$ no considera a la alternabilidad como una prohibición.

Por otro lado, la encuesta aplicada a profesionales del derecho arrojó como resultado que el $100 \%$ de los encuestados consideran al derecho de participación como un derecho Constitucional, esta correcta perspectiva guarda relación con lo enunciado en el capítulo quinto, artículo 61 de la Constitución que hace referencia a los derechos de participación. En consecuencia, los profesionales del derecho consideran en un $69 \%$ la posibilidad de reelección de un candidato cuando se haya efectuado un correcto mandato, así el 31 \% restante optó por la no reelección (ver figura 1). 


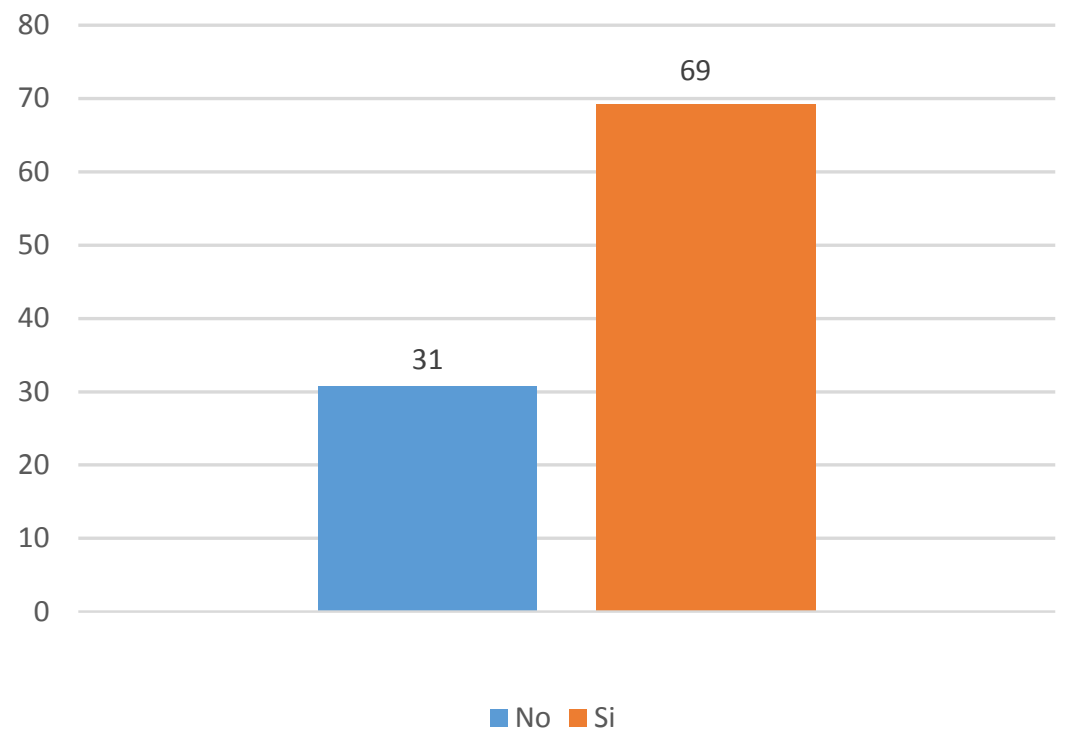

Figura 1. Reelección. Fuente: Encuesta aplicadas a profesionales del derecho.

Con la finalidad de complementar el estudio realizado se tiene que el $92.3 \%$ de los profesionales del derecho conocen el principio de alternabilidad en el Ecuador, observando que tan solo el $8 \%$ no conoce sobre este principio, sin embargo, el $60 \%$ contempló al principio de participación como un elemento constitutivo del Estado, mientras que, el $31 \%$ no consideró al principio de alternabilidad como Derecho Constitucional, este pensamiento guarda concordancia con lo establecido en el artículo 1 de la Constitución, por cuanto el Ecuador es considerado como un Estado constitucional de derechos, democrático, soberano, independiente, unitario, intercultural, plurinacional y laico.

Como consecuencia de los resultados obtenidos, se evidenció un consenso mayoritario entre los encuestados al identificar la problemática de estudio, ya que tanto la ciudadanía como los profesionales del Derecho consideran pertinente la participación ciudadana afirmando la teoría que al prohibir la reelección indefinida se trasgrede el derecho de participación establecido en la Constitución, más aún, cuando ya se reconoció esta figura 
y de forma posterior se eliminó la enmienda constitucional de reelección indefinida, generando una regresión injustificada de derechos constitucionales. En tal sentido, se considera necesario plantear la enmienda a los enunciados 114 y 144 de la Constitución del Ecuador.

\section{PROPUESTA}

Con los resultados obtenidos en la fase de diagnóstico y los postulados y pronunciamientos considerados en el referencial teórico, se demuestra el valor de la participación de los ciudadanos en el ámbito de la política de un Estado; y, la trasgresión al derecho de participación por la aplicabilidad del principio de alternabilidad al prohibir la reelección indefinida, por este motivo, se propone una enmienda a la Constitución de la República del Ecuador considerando los parámetros establecidos en la figura 2.

\section{Enmienda a la Contitución}

articulos 114 y 144
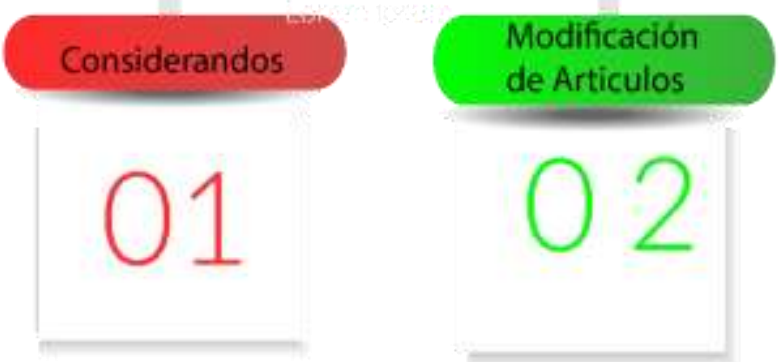

\section{Disposiciones}

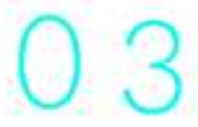

Figura 2. Propuesta de enmienda de la CRE. 


\section{Proyecto de enmienda a la Constitución de la República del Ecuador República del Ecuador Asamblea Nacional \\ El pleno}

\section{Considerando:}

Que, el artículo 3 de la Constitución manda como deber del Estado garantizar sin discriminación alguna el efectivo goce de los derechos establecidos en la Constitución y en los instrumentos internacionales, en particular la educación, la salud, la alimentación, la seguridad social y el agua para sus habitantes.

Que, es necesario fortalecer la consulta popular para que pueda ser ejercida en el ámbito de las competencias de los diferentes niveles de gobierno.

Que, el artículo 25 del Pacto Internacional de los Derechos Civiles y Políticos dispone que todas y todos los ciudadanos gozarán, sin restricciones indebidas, de los derechos a participar en la dirección de los asuntos políticos, directamente o por medio de representantes libremente elegidos; a votar y ser elegidos en elecciones mediante sufragio universal e igual y por voto secreto; $y$, a tener acceso en condiciones generales de igualdad a las funciones públicas de su país.

Que, el artículo 61 numeral 1 de la Constitución de la república determina que las y los ecuatorianos tienen el derecho a elegir y ser elegidos.

Que, el artículo 95 inciso primero de la Constitución manda que las ciudadanas y ciudadanos, en forma individual y colectiva, participarán en la toma de decisiones, planificación y gestión de los asuntos públicos, y en el control popular de las instituciones del Estado y la sociedad.

Que, de conformidad con el artículo 441 de la Constitución para la aprobación de la enmienda se requiere el respaldo de las dos terceras partes de los miembros de la Asamblea Nacional; $y$.

Que, el artículo 441 de la Constitución de la República prescribe que se puede realizar la enmienda de uno o varios artículos de la Constitución cuando no se altere su estructura fundamental, el carácter y elementos constitutivos del Estado, no se establezca 
restricciones a los derechos y garantías y no se modifique el procedimiento de reforma de la Constitución

En uso de sus atribuciones constitucionales y legales, aprueba las siguientes: enmiendas a la Constitución de la República del Ecuador

Artículo. 1.- En el artículo 114, suprímase la frase "reelegirse por una sola vez, consecutiva o no, para el mismo cargo". Añádase luego de la palabra "podrán " la frase: "postularse para reelegirse".

Artículo. 2.- En el artículo 144, en el inciso segundo suprímase la frase "ser reelecto por una sola vez". Añádase luego de la palabra "podrá" la frase: "postularse para ser reelecto".

\section{Disposiciones transitorias}

Primera: Las enmiendas constitucionales a los artículos 114 y 144 segundo inciso de la Constitución de la República del Ecuador, referidas a los derechos de participación política, entrarán en vigencia a partir de su publicación en el Registro Oficial.

\section{Disposición general}

Las Enmiendas Constitucionales aprobadas por el Pleno de la Asamblea Nacional, deberán ser desarrolladas, armonizadas y adecuadas mediante las normas infraconstitucionales en los respectivos cuerpos normativos, sin perjuicio de la vigencia y aplicación del principio de supremacía constitucional según el artículo 424 de la Constitución.

Dado en Quito, Provincia de Pichincha, en la Sala de Sesiones del Pleno de la Asamblea Nacional, a los 29 días del mes de junio de 2020.

\section{DISCUSIÓN}

El derecho de participación se ha definido como la intervención ciudadana en asuntos de la gestión pública, a través de elecciones y votaciones periódicas, justas y auténticas, enmarcadas en procesos democráticos que garanticen su goce efectivo. Por lo tanto, la 
participación corresponde al derecho mediante el cual el poder político puede actuar de manera democrática garantizando que la voluntad de los ciudadanos sea el límite y origen de la legitimidad del ejercicio de su poder.

Queda demostrado en esta investigación que la participación ciudadana es el medio idóneo para que la sociedad pueda expresar su voluntad de forma libre y soberana sobre cuestiones relacionadas con bienes públicos y aspire a desempeñar funciones en cualquier organismo del Estado, bajo el principio de igualdad de condiciones.

En consecuencia, se evidencia que Ecuador vive un desmontaje progresivo del Estado de Derecho al permitir la regresión de los derechos de participación mediante la eliminación de la reelección indefinida a través de la consulta popular efectuada en el año 2018, teniendo esta un fin ilegitimo ya que no se puede permitir la restricción de un derecho reconocido con sustento de la Corte Constitucional ecuatoriana, de este modo, se demuestra que la soberanía de un Estado radica en su pueblo, y que esta voluntad de elegir a sus gobernantes solo puede ser efectuada mediante el sufragio enmarcado en un contexto trasparente y claro, es aquí cuando el principio de alternabilidad surge ya que solo la ciudadanía tiene la potestad de ejercerlo.

Al respecto, tantos los abogados como la ciudadanía que formó parte de esta investigación creen conveniente y oportuna la participación ciudadana dentro de un Estado, para de esta manera, garantizar el efectivo goce de los derechos. Por consiguiente, y a efectos de evitar que se siga transgrediendo el derecho de participación por la limitación a la reelección indefinida, y por no alterar la estructura básica del Estado se propone la enmienda constitucional al artículo 114 y 144 de la Constitución de la República del Ecuador, sobre la base del (Dictamen Nº01-14-DRC-CC, 2014) emitido por la Corte Constitucional del Ecuador que abarcaba una amplia progresión de derechos.

\section{FINANCIAMIENTO}

No monetario. 


\section{AGRADECIMIENTO}

A la Universidad Católica de Cuenca por impulsar el desarrollo de esta investigación.

\section{REFERENCIAS CONSULTADAS}

Asambea Nacional Constituyente. (20 de Octubre de 2008). Constitución de la República del Ecuador;[Constitution of the Republic of Ecuador]. Supremacia de la Constitucion. Montecristi, Manabí, Ecuador: Registro Oficial 449. Obtenido de https://n9.cl/hd0q

Asamblea General de las Naciones Unidas. (10 de diciembre de 1948). Declaración Universal de Derechos Humanos:[Universal Declaration of Human Rights]. Derechos. Paris, Francia. Obtenido de https://n9.cl/XE66

Asamblea Nacional Constituyente. (05 de Junio de 1998). Constitución Política del Ecuador;[Political Constitution of Ecuador]. Derechos Políticos. Riobamba, Chimborazo, Ecuador: Registro Oficial. Obtenido de https://n9.cl/o4tkp

Asamblea Nacional Constituyente. (Veinte de Octubre de 2008). Constitución de la República del Ecuador;[Constitution of the Republic of Ecuador ]. Derechos. Montecristi, Manabi, Ecuador: Registro Oficial 449. Obtenido de https://n9.cl/hd0q

Asamblea Nacional del Ecuador. (21 de Septiembre de 2009). Ley Orgánica de Garantias Jurisdiccionales y Control Constutucional; [Organic Law of Jurisdictional Grants and Constitutional Control]. Control constitucional de las enmiendas, reformas y cambios constitucionales. Quito, Ecuador, Pichincha: Registro Oficial Suplemento 52. Obtenido de https://n9.cl/su7v

Asamblea Nacional del Ecuador. (06 de febrero de 2012). Ley Orgánica Electoral, Código de la Democracia;[ORGANIC ELECTORAL LAW, CODE OF THE DEMOCRACY]. De la Función Electoral. Quito, Pichincha, Ecuador: Registro Oficial suplemento 578. Obtenido de https://n9.cl/p4fh

Baños, J. (2006). Teorías de la Democracia: debates actuales; [Democracy theories: current debates]; recuperado de https://n9.cl/7bqe6. Scielo, 35-58.

Brewer-Carias, A. (2009). allanbrewercarias.net. Obtenido de El Juez constitucional Vs La Alternabilidad;[The Constitutional Judge Vs Alternability].

Dictamen No 001-14-DRC-CC;[Opinión No. 001-14-DRC-CC], Caso № 0001-14-RC (Corte Constitucional 31 de Octubre de 2014). Obtenido de https://n9.cl/4t607 
Held, D. (1991). Modelos de Democracia; [Models of Democracy]; https://n9.cl/rbra. Alianza Editorial Madrid.

Nieto, A. M., \& Romero, C. (2017). Percepción sobre credibilidad en la Democracia y la participación ciudadana en estudiantes de derecho,[Perception of credibility in Democracy and citizen participation in law students]. LOGOS, 2. doi:http://dx.doi.org/10.22335/rlct.v10i1.497

Nivelo, C., Erazo, J., Guerra, M., \& Narváez, C. (2020). Derecho de Paticipación: Constitución de la Republica del Ecuador. Principio de Progresividad de los Dercehos;[Participation Rights: Constitution of the Republic of Ecuador. Principle of]. Iustitia Socialis, Revista Arbitrada de Ciencias Juridícas, 2. doi:http://dx.doi.org/10.35381/racji.v5i8.587

Organización de los Estados Americanos. (22 de Noviembre de 1969). Convención Americana Sobre Derechos Humanos;[American Convention on Human Rights]. Derechos Civiles y Políticos. San Jose, Costa Rica. Obtenido de https://n9.cl/7xhu

Penfold, M., Corrales, J., \& Hernández, G. (2014). Los invencibles; La reelción presidencial y Los cambios Constitucionales en America Latina. SciELO. doi:http://dx.doi.org/10.4067/S0718-090X2014000300002

Robles, P., Erazo, J., Trelles, V., \& Narváez, C. (2020). Consejo de participación ciudadana y control social transitorio del Ecuador:[Council of citizen participation and social transitory control of Ecuador:]. Iustitia Socialis. Revista Arbitrada de Ciencias Jurídicas, 5. doi:http://dx.doi.org/10.35381/racji.v5i8.558

Sanchéz, R. (2003). Política, Democracia y Ciudadnia; [Politics, Democracy and Ciudadnia]; https://n9.cl/kadcd. Universidad de Rosario, 8-37. doi:http://dx.doi.org/10.12804/revistas.urosario.edu.co/desafios/a.6094

Sentencia Constitucional Plurinacional 0084/2017, 20960-2017-42-AIA (Tribunal Constitucional Plurinacional 28 de Novimebre de 2017). Obtenido de https://n9.cl/ykmu

Sentencia N018-18-SIN-CC, [Judgment No. 018-18-SIN-CC], Causas N0099-15-IN, 100-15IN, 0102-15-IN, 001-16-IN, 0002-16-IN, 003-16IN, 0004-16-IN, 005-16-IN, 0006-16-IN y 008-16-IN (Corte Constitucional del Ecuador 2018). Obtenido de https://n9.cl/5bu4

Serrafero, M. D. (2011). La Reeelción en America Latina;[Reelection in Latin America];recuperado de https://n9.cl/ojtw. Revista de Instituciones Ideas y Mercados, 8. 
Iustitia Socialis. Revista Arbitrada de Ciencias Jurídicas.

Año V. Vol. V. №2. Edición Especial. 2020-II

Hecho el depósito de Ley: FA2016000064

ISSN: 2542-3371

FUNDACIÓN KOINONIA (F.K). Santa Ana de Coro, Venezuela

Raul Andres Ortega-Pineda; Cecilia Ivonne Narváez-Zurita; Juan Carlos Erazo-Álvarez; José Luis Vázquez-Calle

(C2020 por los autores. Este artículo es de acceso abierto y distribuido según los términos y condiciones de la licencia Creative Commons Atribución-NoComercial-Compartirlgual 4.0 Internacional (CC BY-NC-SA 4.0) (https://creativecommons.org/licenses/by-nc-sa/4.0/). 